adolescents. Today relevant concepts and trusted techniques exist. There are textbooks and journals whose subject matter is devoted entirely to adolescents. Things have improved.

But what about the serious deficits outlined by the Peter Horrocks team and other reports? What can be done? The Health Advisory Service has no executive function. It simply provides advice. Action must come from elsewhere. In many parts of the country the adolescent services have to compete with demands for adult psychiatric services. The lack of initiative from adult psychiatrists is precisely the reason that the Ministry of Health had to lean on Regional Hospital Boards 20 years ago. The current absence of response from the psychiatric profession and the Health Boards to the HAS Report would indicate that unless there is Government initiative, the scandalous shortage of adolescent facilities in parts of the country will continue.

But apart from developing new resources the document draws attention to another serious issue, namely the need for more training facilities. Until now the Child and Adolescent Psychiatry Section of the Joint Committee for Higher
Psychiatric Training has rightly devoted its energies to improving training in child psychiatry. In contrast, the training for adolescent psychiatrists remains seriously flawed. The constant stream of trainees seconded for six month periods to the Edinburgh Adolescent Service illustrates the existing shortage of training facilities in England and Wales. Newly appointed consultants in adolescent psychiatry may still receive only six months full-time training in their own speciality! Because of their limited training and lack of opportunity to master existing techniques and concepts, inevitably such specialists need to be ultra-selective in the services they provide.

To overcome the problem it may be that the training of adolescent psychiatrists has to become separate from that of child psychiatrists, but with foresight and initiative that outcome can be avoided to the benefit of both groups. We as a profession have the remedy in our own hands.

In the meantime we must thank the HAS for highlighting long-standing inadequacies in the psychiatric services for disturbed adolescents in terms of resources and the need for more training.

\title{
Cheadle Royal Hospital Prize
}

An annual prize of $£ 500$ will be awarded for research at consultant level. The competition is open to all consultant psychiatrists in the North West Division of the College, excluding full-time senior academic staff. Material published in the previous year may be included, as may previously submitted research for a higher qualification, provided a substantial amount of the work has been done while in a consultant post.
The adjudicators will comprise the Professors currently Heads of Department at Liverpool and Manchester Universities, together with the Medical Superintendent of Cheadle Royal Hospital.

Entries to be submitted to the Chairman of the North West Division of the Royal College of Psychiatrists by 31 March 1988.

\section{Study Team on Quality of Community Care}

The Richmond Fellowship and MIND have joined forces to set up a Study Team on the quality of community care. Both organisations are concerned at the lack of services for those leaving mental hospitals.

The Study Team will parallel the Griffiths Review. Sir Roy Griffiths is concerned with the organisation and management of community care and with finding more effective and efficient ways of spending existing money. The Richmond
Fellowship/MINDStudy Team will look at how an effective community care service can be developed for mentally ill people and then calculate a reasonable cost for such a service. It plans to issue a report in April 1988 to complement the Griffiths Review. The Richmond Fellowship/MINDcall for evidence to be provided to the Study Team. Its secretary is Chris Heginbotham, National Director of MIND, 22 Harley Street, London WIN 2ED (telephone 01637 0741).

\section{Correction}

Accountability and Delegation. J. H. Henderson. (Correspondence, Bulletin, October 1987). In paragraph 8 beginning "The 1959 Mental Health Act...." the second reference to the "Responsible Medical Officer" was incorrectly printed as "Registered Medical Officer". This, too, should read "Responsible Medical Officer". 